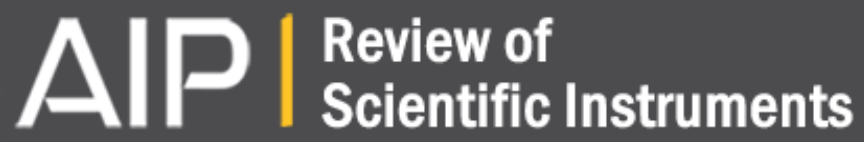

A new cell design for off-axis amplification of ultrashort dye lasers which uses total internal reflection

T. Bultmann, D. Bingemann, N. P. Ernsting, D. Schwarzer, and L. Nikowa

Citation: Review of Scientific Instruments 66, 4393 (1995); doi: 10.1063/1.1146436

View online: http://dx.doi.org/10.1063/1.1146436

View Table of Contents: http://scitation.aip.org/content/aip/journal/rsi/66/8?ver=pdfcov

Published by the AIP Publishing

\section{Articles you may be interested in}

Simulated fabrication of off-axis microlens array using excimer laser dragging process

J. Laser Appl. 18, 305 (2006); 10.2351/1.2355522

Improved uniformity of multielement thin films prepared by off-axis pulsed laser deposition using a new heater design

Rev. Sci. Instrum. 67, 3229 (1996); 10.1063/1.1147447

Design and performance of microstrip resonators using YBCO thin films made by in situ off-axis sputtering AIP Conf. Proc. 273, 122 (1992); 10.1063/1.43620

Eigenfrequencies of a cylindrical cavity with an internal off-axis spherical obstacle J. Acoust. Soc. Am. 82, S107 (1987); 10.1121/1.2024556

COHERENT RAMAN EFFECT IN THE OFF-AXIS RAMAN LASER RESONATOR Appl. Phys. Lett. 4, 185 (1964); 10.1063/1.1753931

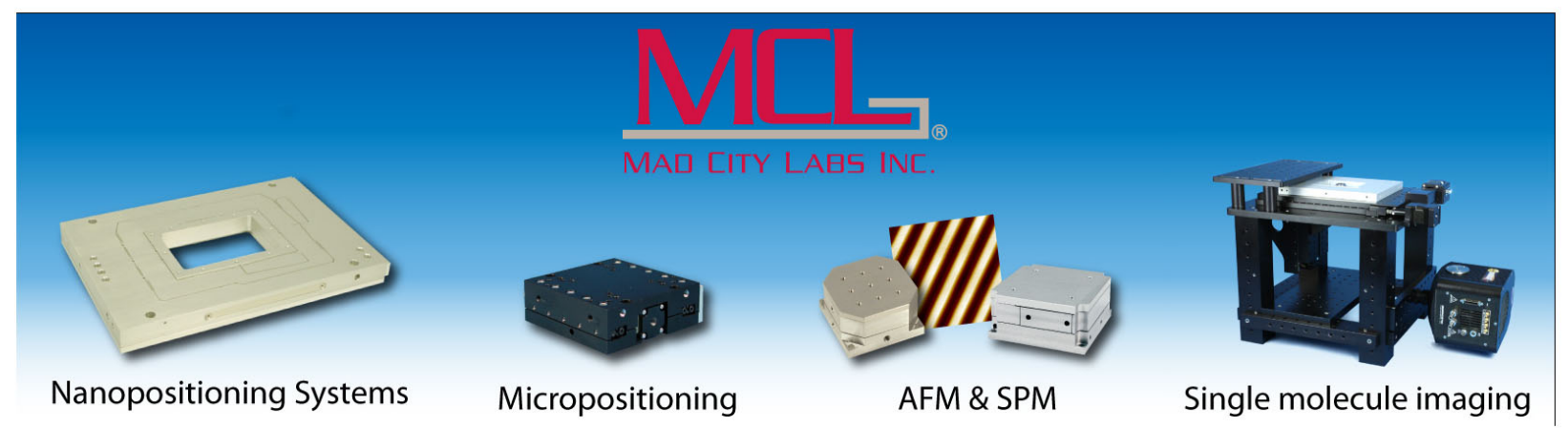




\title{
A new cell design for off-axis amplification of ultrashort dye lasers which uses total internal reflection
}

\author{
T. Bultmann, D. Bingemann, and N. P. Ernsting ${ }^{\text {a) }}$ \\ Institut für Theoretische und Physikalische Chemie, Humboldt-Universität zu Berlin, Bunsenstr. 1, \\ D-10117 Berlin, Germany \\ D. Schwarzer and L. Nikowa \\ Max-Planck-Institut für Biophysikalische Chemie, Abt. Spektroskopie und Photochemische Kinetik, Postfach \\ 2841, D-37077 Göttingen, Germany
}

(Received 23 February 1995; accepted for publication 23 April 1995)

A new cell design for off-axis amplification of femtosecond dye lasers which uses total internal reflection is reported. Compared to the conventional on-axis configuration, these amplifiers produce less amplified spontaneous emission in the far field and maintain the input beam profile. (-) 1995 American Institute of Physics.

Here we report a major change to our excimer-laser pumped, pulsed colliding-pulse mode-locked (CPM) dyelaser amplification. ${ }^{1}$ In that arrangement we followed the approach of Rolland and Corkum ${ }^{2}$ and used three prismatic capillary dye cells ${ }^{3,4}$ with increasing diameter for the amplification. Capillary cells are well suited for the amplification of beams with diameters above $1 \mathrm{~mm}$. However for optimum utilization of pump energy, the first amplification stage should have highest gain at much smaller diameters. Here one may employ the conventional, transversally pumped cell configuration. ${ }^{5}$ In this case the side window, which is necessary for optical pumping, clips the stimulating beam and thus leads to diffraction and severe disturbance of the beam profile after amplification. This problem has been solved in principle by an off-axis amplification geometry in which the stimulating beam is reflected internally at the side window. ${ }^{6}$ So far, conventional quartz cells have been used in this scheme. For quartz cells and for typical solvents and wavelengths in the visible, the refractive index of the dye solution

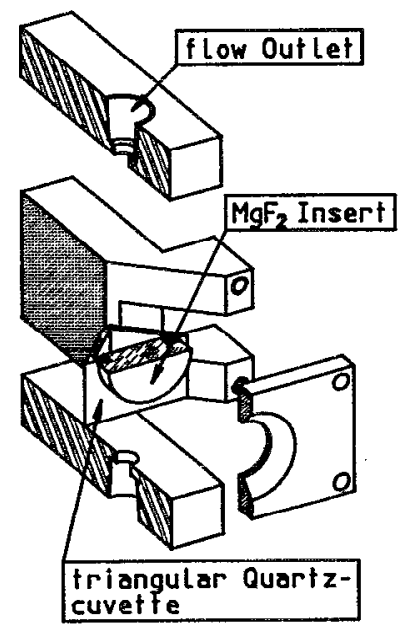

FIG. 1. Short dye cell for off-axis amplification using total internal reflection with near-Brewster angles for the amplified beam.

"To whom correspondence should be addressed. is smaller than that of the window material so that internal reflection is accompanied by a transmission loss of more than $50 \%$.

Transmission loss accompanying internal reflection can be overcome by using a side window for optical pumping which is made from magnesium difluoride $\left(\mathrm{MgF}_{2}\right.$; $\left.n_{[616 \mathrm{~nm}]}=1.388913\right)$ and a solvent with a higher index of refraction. With ethylene glycol as the solvent $(n \approx 1.4306)$ the critical angle for total internal reflection is $\theta_{c}=76.13^{\circ}$. It is also possible to use propylene carbonate $(n \approx 1.4210)$ or a mixture of ethylene glycol and methanol up to 3:2 (by volume) instead of the highly viscous ethylene glycol. The construction of two different, novel amplification cells using $\mathrm{MgF}_{2}$ pump windows for total internal reflection is shown in Figs. 1 and 2.

The first cell is constructed from a quartz cuvette with a right-angled triangular cross section (height; $45 \mathrm{~mm}$; internal width of hypotenuse surface $10.0 \sqrt{2} \mathrm{~mm}$; Helma No. 101.061-QS). A circular hole with a diameter of $10.1 \mathrm{~mm}$ was drilled centrally in the hypotenuse surface. From the

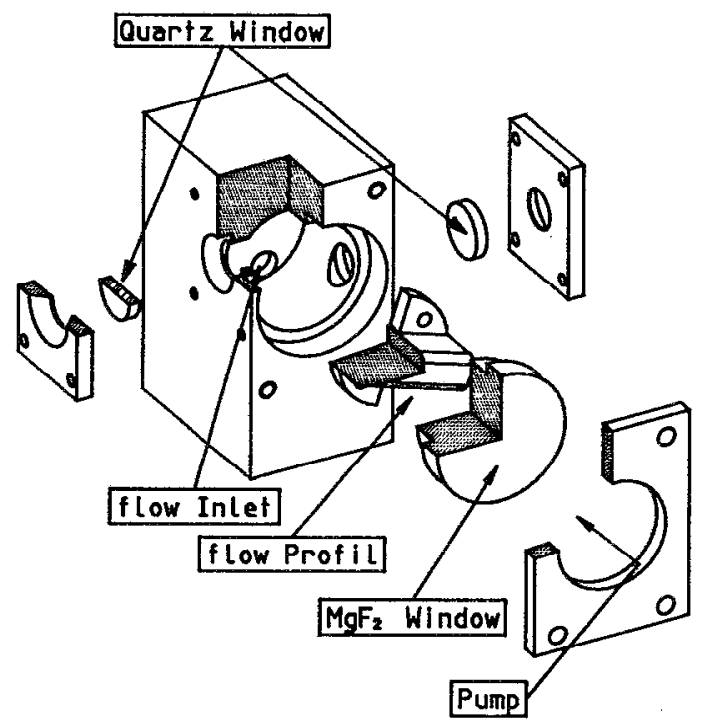

FIG. 2. Long dye cell for off-axis amplification using total internal reflection. 


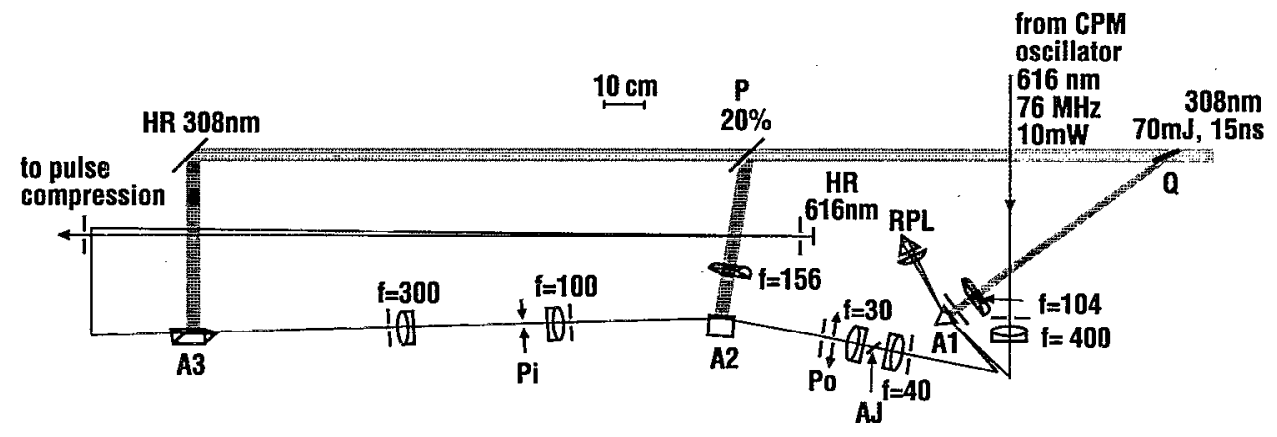

FIG. 3. Novel arrangement for femtosecond dye-laser amplification. [Q: quartz fiat, RPL: roof prism with lens, A1: first amplifier (compare Fig. 1), AJ: absorber jet, Po: polarizer selecting horizontal polarization, A2: second amplifier (compare Fig. 2), Pi: $150 \mu \mathrm{m}$ pinhole, A3: third amplifier (Bethune cell, diameter $3 \mathrm{~mm}$ ). Focal lengths are given in millimeters.]

outside a $\mathrm{MgF}_{2}$ pump window fits into the hole such that its inside surface protrudes $\sim 0.5 \mathrm{~mm}$ into the dye solution. The $\mathrm{MgF}_{2}$ window is sealed by a silicone rubber O-ring against the quartz window and held by a mechanical support (compare Fig. 1). The quartz cuvette itself was glued (with silicone glue, Wacker E41) into a holder that allowed for flow of the dye solution. If the stimulating beam enters the cell at Brewster's angle for horizontal polarization (calculated for ethylene glycol), then the resulting angle for internal reflection, at $79.95^{\circ}$, is larger than the critical angle $\theta_{c}=76.13^{\circ}$ for total internal reflection. After passing through the cell, the amplified beam deviates by $20.1^{\circ}$ from the original beam direction (see Fig. 3). In practice the angle of incidence for the stimulating beam is increased slightly above Brewster's angle in order to allow for a wider angular range for total internal reflection.

The triangular cell is operated with a $1.1 \mathrm{mM}$ solution of sulforhodamine B in ethylene glycol. It is pumped with approximately $1 \mathrm{~mJ}$ at $308 \mathrm{~nm}$ on a length of $5 \mathrm{~mm}$. Two passes are made through the gain medium. At the first pass the stimulating beam has a diameter of about $0.4 \mathrm{~mm}$, the focus lying slightly behind the exit window. Retroreflection after the first passage, and at a slightly different angle is obtained by means of a retroreflecting prism and a planoconvex lens $(f=300 \mathrm{~mm})$ glued to it (see Fig. 3). A circular aperture $(\varnothing=1.5 \mathrm{~mm})$ in front of the lens defines a small solid angle for the amplification and is necessary to prevent feedback of amplified spontaneous emission (ASE) in the second pass. The diameter of the stimulating pulse is somewhat larger at the second pass and again the focus lies behind the exit window. After two passes through this cell the beam is sent through a saturable absorber $(100 \mu \mathrm{m}$ thick jet of malachite green in ethylene glycol, with optical density $>5$ at $616 \mathrm{~nm}$ ). The pulse energy after the saturable absorber is about $1 \mu \mathrm{J}$. This corresponds to a total gain of more than $10^{4}$ up to this stage.

The construction of the second cell is shown in Fig. 2. It consists of a mechanical body, one $\mathrm{MgF}_{2}$ side window (diameter $20.0 \mathrm{~mm}$ ) for optical pumping, and two windows made of quartz. The cell is operated with a $0.95 \mathrm{mM}$ solution of sulforhodamine B in ethylene glycol and pumped with 12 $\mathrm{mJ}$ at $308 \mathrm{~nm}$. Care has to be taken not to focus the pump beam too tightly since this might lead to deposition of the dye in the pump focus. This would result in high losses for the reflected beam. In order to prevent lasing from the entrance and exit windows, the cuvette is tilted around a horizontal axis which is perpendicular to the propagation direction. The stimulating beam has a diameter of $\sim 1 \mathrm{~mm}$; its focus lies $20 \mathrm{~cm}$ behind the exit window of the cell. The angle of incidence is chosen such that total internal reflection occurs over the whole length of the $\mathrm{MgF}_{2}$ pump window. The output energy after a single pass is typically $35 \mu \mathrm{J}$ with less than $0.3 \%$ ASE. After spatially filtering with a pinhole of $150 \mu \mathrm{m}$ diameter this energy is further amplified to $240 \mu \mathrm{J}$ $\left(\mathrm{ASE}<1 \%\right.$ ) with a Bethune cell ${ }^{3,4}$ (diameter $3 \mathrm{~mm}$, length 40 $\mathrm{mm}$; radiant dyes RBZ; $0.23 \mathrm{mM}$ rhodamin 101 in methanol). The best results-in terms of energy extraction and beam profile-are obtained when the stimulating beam is sent slightly convergent through the cell (waist $\sim 5-7 \mathrm{~m}$ away) with a diameter such that the capillary of the Bethune cells intercepts the central Airy disk. The cell is pumped with all of the remaining excimer-laser energy. The overall setup of the amplification is shown in Fig. 3.

We are using the second type of dye cell (Fig. 2) for amplification of a CPM dye laser, a synchronously pumped antiresonant ring dye laser (both operating at $616 \mathrm{~nm}$ ) and in a distributed-feedback-dye-laser-type setup at $470 \mathrm{~nm} .^{7,8}$ This cell can also be used for the amplification of conventional excimer-or YAG-pumped dye lasers with nanosecond pulse duration. (In the latter case, the temporal substructure of the pump pulse should be controlled or averaged in order to obtain high gain without fluctuation of the amplified pulse energy from shot to shot). In all applications this cell will give higher energy and less ASE compared to transversally pumped dye cells in an on-axis configuration. However, its most valuable property is that it preserves the input beam profile for subsequent nonlinear applications.

\footnotetext{
${ }^{1}$ N. P. Ernsting and M. Kaschke, Rev. Sci. Instrum. 62, 600 (1991).

${ }^{2}$ C. Rolland and P. B. Corkum, Opt. Commun. 59, 64 (1986).

${ }^{3}$ D. S. Bethune, Appl. Opt. 20, 1897 (1981).

${ }^{4}$ D. J. Brink and C. J. van der Hoeven, Rev. Sci. Instrum. 55, 1948 (1984).

${ }^{5}$ R. L. Fork, C. V. Shank, and R. T. Yen, Appl. Phys. Lett. 41, 223 (1982).

${ }^{6}$ S. Szatmári, G. Almási, and P. Simon, Appl. Phys. B 53, 82 (1991).

${ }^{7}$ D. Bingemann and N. P. Ersting, J. Chem. Phys. 102, 2691 (1995).

${ }^{8}$ P. Simon, S. Szatmári, and F. P. Schäfer, Opt. Lett. 16, 1569 (1991).
} 